\title{
Laparoscopic Extraperitoneal Radical Prostatectomy
}

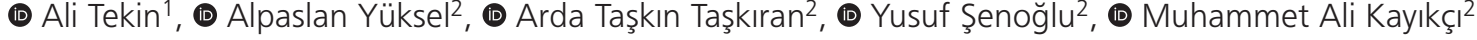 \\ ${ }^{1}$ Acıbadem University, Atakent Hospital, Clinic of Urology, Istanbul, Turkey \\ 2Düzce University Faculty of Medicine, Department of Urology, Düzce, Turkey
}

\begin{abstract}
Radical prostatectomy (RP) involves removing the entire prostate with its capsule intact and the seminal vesicles (SV). In this video article, we summarized the extraperitoneal laparoscopic RP with pelvic lymph node dissection procedure along with a video presentation of a case. The patient is placed in a Trendelenburg position. Through a small transverse infraumblical incision, the anterior rectus aponeurosis is identified and incised. The extraperitoneal surgical field is developed bluntly by a balloon dilator, and a $10 \mathrm{~mm}$ trocar is placed for the camera. $\mathrm{CO}_{2}$ insufflation at a $12-15 \mathrm{mmHg}$ pressure is established, and the remaining trocars are placed. The fatty tissue is swept laterally to create a wide operative field. The endopelvic fascia is incised on both sides. The levator ani muscle fibers are separated from the lateral surface of the prostate. Dorsal vascular complex (DVC) is ligated with 2 consecutive sutures. Identification of the bladder neck (BN) is critical for proper dissection between the prostate and the BN. BN is incised until the catheter is seen. The urethral catheter is removed and a Bougie dilator is inserted through the urethra to elevate the prostate. With posterior oblique dissection, the vasa deferentia are exposed and clip-ligated, and SVs are identified and freed. Then, lateral pedicles are ligated with hemoclips and divided. Lateral dissection proceeds with an anterolateral incision from the base to the prostatic apex. The neurovascular bundles lie posterolateral to the prostate. Apical dissection and division of the DVC and urethra is a critical step to ensure a safe surgical margin and good postoperative erectile function and continence. The urethra is divided with a small rim on the prostate. The gland is totally freed, put into an endobag, and extracted. The vesicourethral anastomosis is done using two 3-0 monocryl sutures in a running fashion, starting from the posterior in both direction and tied together at the 12 o'clock position, anteriorly.
\end{abstract}

Keywords: Prostate cancer, radical prostatectomy, extraperitoneal, laparoscopy

Radical prostatectomy (RP) involves removing the entire prostate with its capsule intact and the seminal vesicles (SV). The surgical technique has evolved from open to a laparoscopic and robotassisted technique. RP is mostly indicated for the treatment of intermediate-risk and high-risk localized prostate cancer. In this video article, we summarized the extraperitoneal laparoscopic RP with pelvic lymph node dissection procedure along with a video case presentation.

The patient is placed in a Trendelenburg position with a $25^{\circ}$ head-down tilt. The surgeon stands on the left and the assistant on the right side. Through a small transverse incision just caudal to the umbilicus, the anterior rectus aponeurosis is identified and incised. The extraperitoneal surgical field is developed bluntly first by finger dissection and then a balloon dilator. A $10 \mathrm{~mm}$ trocar is placed for the camera. $\mathrm{CO}_{2}$ insufflation at a 12 $15 \mathrm{mmHg}$ pressure is established and the remaining trocars are placed under direct visual control in a reverse $V$ configuraiton.

The fatty tissue is swept laterally to create a wide operative field until the myopectineal area is seen. The endopelvic fascia that is cleaned from fatty tissue is incised on both sides. The levator ani muscle fibers are separated from the lateral surface of the prostate. The puboprostatic ligaments are exposed and divided. Dorsal vascular complex (DVC) is ligated with 2 consecutive sutures (30 $\mathrm{mm}$ polyglactin $\mathrm{MH} 2 / 0$ ).

Identification of the bladder neck (BN) is critical for proper dissection between the prostate and the $\mathrm{BN}$, for which caudal traction of the catheter balloon can be helpful. BN is incised horizontally with a hook dissector or ultrasonic scsissors until the catheter is seen. The urethral catheter is removed and a Bougie dilator is inserted through the urethra to elevate and fix the prostate. Posterior BN is incised horizontally. Caution should be exercised while dissecting to avoid entry into the prostate. With posterior oblique dissection, vasa deferentia are exposed and clip-ligated. SVs are identified and freed from the surrounding fatty tissues. Thermal energy should be kept at minimum to avoid thermal damage to the nearby nerve bundles. Then, lateral pedicles are ligated with hemoclips and divided.

Anterior traction of the SVs and vasa deferentia helps with the identification and in developing the posterior plane correctly, between the two layers of Denonvilliers fascia (i.e. interfascial

Cite this article as: Tekin A, Yüksel A, Taşkıran AT, Şenoğlu Y, Kayıkçı MA. Laparoscopic Extraperitoneal Radical Prostatectomy. Bull Urooncol 2020;19:164-166

Address for Correspondence: Ali Tekin, Acıbadem University, Atakent Hospital, Clinic of Urology, İstanbul, Turkey

E-mail: aalitekin@hotmail.com ORCID-ID: orcid.org/0000-0001-7438-0251 Received: 04.08.2020 Accepted: 07.08.2020 
dissection). Dissection continues bluntly in the caudal direction to the prostatic apex and laterally to the medial aspect of the neurovascular bundles.

Lateral dissection proceeds with an anterolateral incision from the base to the prostatic apex. The neurovascular bundles lie posterolateral to the prostate. With the prostatic fascia kept intact, the bundles are released from the prostate.

Apical dissection and division of the DVC and urethra is a critical step to ensure a safe surgical margine and good postoperative erectile function and continence. As the anatomy of the apex is highly variable, visualization and careful dissection is needed. The urethra is divided with a small rim on the prostate. The gland is totally freed, put into an endobag, and extracted at the end of the operation.

The vesicourethral anastomosis is done using two 3-0 monocryl sutures in a running fashion, starting posteriorly in both directions and tied together at the 12 o'clock position, anteriorly. The urethral catheter is removed on the $8-10^{\text {th }}$ postoperative day.

\section{Acknowledgements}

Publication: The results of the study were not published in full or in part in form of abstracts.

Contribution: There is not any contributors who may not be listed as authors.

Conflict of Interest: No conflict of interest was declared by the authors.

\section{Ethics}

Informed Consent: Patient approval was obtained.

Peer-review: Externally and internally peer-reviewed.

\section{Authorship Contributions}

Concept: A.T., A.Y., Design: Y.Ş., A.T.T., Data Collection or Processing: A.Y., A.T.T., Analysis or Interpretation: A.T., A.Y., Y.Ş., Literature Search: A.T., M.A.K., Writing: A.T., A.Y. 